\title{
$\gamma$-Glutamyl Transferase: Studies of Normal and Cystinotic Human Leukocytes, Rabbit Neutrophiles, and Rat Liver
}

\author{
A. DESMOND PATRICK, RICHARD D. BERLIN, AND JOSEPH D. SCHULMAN
}

\begin{abstract}
Department of Chemical Pathology, Institute of Child Health, University of London, London, United Kingdom and Department of Physiology, University of Connecticut Health Center, Farmington, Connecticut, and Section on Human Biochemical and Developmental Genetics, National Institute of Child Health and Human Development, National
\end{abstract}

Institutes of Health, Bethesda, Maryland, USA

\section{Summary}

Evidence has been obtained in three different cell types, by a combination of biochemical and histologic approaches, that some $\gamma$-glutamyl transferase (EC $\mathbf{2}$.3.2.2) activity is associated with lysosomes. The distribution of $\gamma$-glutamyl transferase in subcellular fractions of human leukocytes and its enrichment in a postnuclear granule fraction were similar to the corresponding findings for lysosomal marker enzymes. Isopycnic centrifugation of the postnuclear fraction showed that although the bulk of the $\gamma$ glutamyl transferase activity was associated with nonlysosomal particles containing alkaline phosphatase, a clearly separated fraction (approximately $20 \%$ ) comigrated with lysosomal marker enzymes. L-cystine was the most potent of the amino acids tested as acceptors of the $\gamma$-glutamyl moiety of $L-\gamma$-glutamyl-P-nitroanilide. Apparent $K_{m}$ for L-cystine was $1.3 \mathrm{mM}$ compared to $8.7 \mathrm{mM}$ for L-glutamine, the second best amino acid acceptor. Optimum pH for the transferase was 9.0; there was no activity below pH 6. Further evidence that leukocyte $\gamma$-glutamyl transpeptidase includes a lysosomal component was obtained by demonstrating histochemically that the transpeptidase appears in cytoplasmic granules in rabbit neutrophile bone marrow precursors at a time when the synthesis of azurophile (lysosomal) granules is predominant.

In addition, relative specific activity of the enzyme in the liver lysosomal fraction of rats preinjected with Triton WR-1339 was approximately 11. A comparison of its distribution with that of marker enzymes for the different subcellular fractions suggested that the lysosomal $\gamma$-glutamyl transferase activity is not accounted for by contamination with plasma membranes, endoplasmic reticulum or mitochondria.

The possible mediation of amino acid transport by the transferase, for which cystine is an excellent $\gamma$-glutamyl acceptor, and a lysosomal location of some of the enzyme activity suggested that its deficiency might explain the intralysosomal storage of cystine in cystinosis. In these studies, however, no evidence was found for an abnormality of the enzyme in cystinotic leukocytes.

\section{Speculation}

The suggestion that $\gamma$-glutamyl transpeptidase is a significant mediator of mammalian amino acid transport, and particularly the transport of cystine, has found little support in our present or previous investigations. The transpeptidase clearly catabolizes glutathione and has a complex intracellular distribution including an association with lysosomal particles, but its further functions, if any, and the significance of its subcellular localization remain to be defined.

$\gamma$-Glutamyl transferase (EC 2.3.2.2) catalyzes the breakdown of glutathione (L- $\gamma$-glutamyl-L-cysteinylglycine) by a reaction involv- ing the transfer of the $\gamma$-glutamyl moiety to an amino acid acceptor and the release of cysteinyl-glycine $(5,6,17,18,22)$. Cysteinylglycine is hydrolyzed to its constituent amino acids by a peptidase, and $\gamma$-glutamyl-cyclotransferase (EC 2.3.2.4) acts on the $\gamma$-glutamyl-amino acid to liberate the amino acid and convert the glutamyl residue to 5-oxoproline (13). A link between these reactions, and those of glutathione synthesis catalysed by $\gamma$-glutamylcysteine synthetase (EC 6.3.2.2) and glutathione synthetase (EC 6.3.2.3) was provided by the discovery of 5-oxoprolinase that converts 5oxoproline to glutamate in an ATP-dependent step (43). This series of reactions thus forms a cycle, for each turn of which the $\gamma$-glutamyl moiety of glutathione acts as an acceptor for an amino acid molecule. The quantitative relationships of the enzymes of the cycle and the high activity of membrane-bound $\gamma$-glutamyl transferase in sites known to be involved in amino acid transport, such as the renal proximal tubule, the choroid plexus, and the ciliary body of the eye, have led to the hypothesis that the $\gamma$ glutamyl cycle functions in the translocation of amino acids across cell membranes, thus providing a general mechanism for their transport $(9,22,23,39)$.

Although there is contrary evidence $(27,32)$ that the transpeptidase may not play a substantial role in amino acid uptake into human renal cells or fibroblasts, it is relevant to inquire whether it might be active in intracellular transport, carrying amino acids between subcellular organelles and the cell sap. The digestive processes of the lysosomal system produce amino acids and small peptides from protein breakdown and these products are thought to cross the lysosomal membrane to be reused in synthetic or degradative reactions. In order to investigate whether $\gamma$-glutamyl transferase might be involved in this transport process, we have measured the activity of the enzyme in lysosomal fractions of human leukocytes and of the livers of rats pretreated with Triton WR-1339, and examined rabbit neutrophile precursors for histochemical evidence of a lysosomal transpeptidase component. The authors have also investigated whether the enzyme might be deficient in cystinotic patients, in whose tissues there is gross accumulation of intralysosomal cystine $(26,31)$.

\section{MATERIALS AND METHODS}

All reagents used were highest purity or AnalaR grades.

\section{ISOLATION OF HUMAN LEUKOCYTE SUBCELLULAR FRACTIONS}

Leukocytes were isolated from fresh heparinized human blood drawn from normal volunteers or patients with childhood nephropathic cystinosis, by mixing with 2 vol of $3 \%(\mathrm{w} / \mathrm{v})$ dextran in $0.9 \% \mathrm{NaCl}$ solution and allowing the erythrocytes to sediment under gravity at room temperature for $25 \mathrm{~min}$. All subsequent procedures were carried out at $4^{\circ} \mathrm{C}$. The leukocyte-rich supernatant (averaging 55\% granulocytes) was centrifuged at $600 \mathrm{~g}$ for 5 min (MSE Mistral 6L) and the contaminant erythrocytes in the 
pellet were removed by hypotonic lysis (30). After centrifugation at $600 \mathrm{~g}$ for $5 \mathrm{~min}$ and careful removal of erythrocyte ghosts, the leukocyte pellet was washed once and resuspended in $0.25 \mathrm{M}$ sucrose solution $(1.0 \mathrm{ml}$ for $10 \mathrm{ml}$ blood). The cells were then disrupted by sonication at $20 \mathrm{kHZ}$ for $12 \mathrm{sec}$ with a $50 \mathrm{~W}$ ultrasonic disintegrator (Ultrasonics Ltd., Shipley, Yorks). These conditions resulted in only a small release of acid hydrolases into solution. Nuclei $(\mathrm{N})$ were removed by centrifugation in conical glass tubes at $600 \mathrm{~g}$ for $10 \mathrm{~min}$ (Mistral 6L), followed by the isolation of postnuclear (PN) and supernatant (S) fractions by centrifugation of the $600 \mathrm{~g}$ supernatant at $27,000 \mathrm{~g}$ for $10 \mathrm{~min}$ (MSE Superspeed 50 with $10 \times 10 \mathrm{ml}$ angle rotor, $r_{a v} 5.6 \mathrm{~cm}$ ). The PN fraction was washed by suspension in sucrose solution $(1 \mathrm{ml})$ and recentrifuged at $27,000 \mathrm{~g}$ for $10 \mathrm{~min}$. The $\mathrm{N}$ and PN fractions were finally homogenized in water $(0.5 \mathrm{ml})$ and frozen-thawed twice before assay.

A granulocyte concentrate (average $94 \%$ granulocytes) was prepared by a modification of the above procedure. Up to $20 \mathrm{ml}$ of the leukocyte-rich supernatant obtained after sedimentation of whole-blood in dextran were layered on $8 \mathrm{ml}$ of Lymphoprep (Nyegaard \& Co., Oslo) and centrifuged at $400 \mathrm{~g}$ for $40 \mathrm{~min}$ at $20^{\circ} \mathrm{C}$. The resulting granulocyte pellet was then treated in exactly the same way as the mixed leukocyte pellet obtained by the usual method of centrifugation of the dextran supernatant.

\section{SUCROSE GRADIENT CENTRIFUGATION OF PN SUPERNATANT FRACTION}

For isopycnic sucrose gradient centrifugation, $0.4 \mathrm{ml}$ of the 600 $g$ PN supernatant was layered on a sucrose gradient, density 1.151.30 (consisting of seven $0.3 \mathrm{ml}$ layers of approximately equal density increment, allowed to diffuse for $3 \mathrm{hr}$ at $4^{\circ} \mathrm{C}$ ). The tubes were centrifuged at $115,000 \mathrm{~g}$ for $2 \mathrm{hr}$ (MSE Superspeed 50 with $3 \times 3 \mathrm{ml}$ swingout rotor, $\mathrm{r}_{\mathrm{av}} 7.1 \mathrm{~cm}$ ). Twenty-five $0.1 \mathrm{ml}$ fractions were collected into calibrated tubes through the bottom of the centrifuge tube with a tube-piercer (MSE Ltd, London). Corresponding fractions were pooled and frozen-thawed three times before assay.

\section{DEMONSTRATION OF TRANSPEPTIDASE IN SUBCELLULAR} GRANULES IN RABBIT NEUTROPHILE PRECURSORS

Demonstration of $\gamma$-glutamyl transpeptidase activity was made using a modification of the histochemical procedure of Rutenberg et al. (29). Rabbit bone marrow was diced, filtered through gauze, and the mature erythrocytes removed by hypotonic lysis. Marrow was then fixed in suspension with $1 \%$ paraformaldehyde in phosphate buffered saline for $20 \mathrm{~min}$ on ice. The procedure then followed Rutenberg et al. using $\gamma$-glutamyl-4-methoxy-2-naphthylamide as substrate and coupling the naphthylamide product with Fast blue BBN (diazotized 4'-amino-2',5'-diethoxybenzanilide). Controls were processed identically, but with omission of the $\gamma$-glutamyl substrate. Using $0.1 \%$ Triton-X 100 extracts of marrow, it was shown that the fixation procedure depressed transpeptidase activity against $\mathrm{N}$-( $\gamma$-glutamyl) anilide by less than $10 \%$.

\section{ISOLATION OF RAT LIVER LYSOSOMES}

For the isolation of Triton WR-1339-loaded lysosomes, adult albino rats (approximately $200 \mathrm{~g}$ ) were injected ip with $2 \mathrm{ml}$ of a $10 \%(\mathrm{w} / \mathrm{v})$ aqueous solution of Triton WR-1339 (Serva Biochemicals, Heidelberg). Three days later, after fasting overnight, the rats were killed by stunning and decapitation. The livers were removed on ice, pooled $(10 \mathrm{~g})$ and homogenized in $10 \%(\mathrm{w} / \mathrm{v})$ sucrose solution $(30 \mathrm{ml})$ in 2 passes of a Teflon pestle $(\mathbf{A}$. $\mathbf{H}$. Thomas Co., Philadelphia, PA) rotating at $700 \mathrm{rpm}$. The homogenate was centrifuged at $1000 \mathrm{~g}$ for $10 \mathrm{~min}$ (Mistral 6L) to yield a nuclear $(\mathrm{N})$ fraction; the supernatant was further centrifuged at $25,000 \mathrm{~g}$ for $10 \mathrm{~min}$ (MSE Superspeed $50,10 \times 10 \mathrm{ml}$ rotor) to yield a combined supernatant plus fluffy residue fraction $(25 \mathrm{~S})$ and pellets which were combined and resuspended in $45 \%(w / w)$ sucrose $(8 \mathrm{ml})$. The suspension was equally divided between three $10 \mathrm{ml}$ tubes of the Spinco SW 39L rotor. Mitochondrial (M) and lysosomal (L) fractions were prepared from the $25,000 \mathrm{~g}$ pellet after the method of Trouet (41). Each suspension was layered over with $34.5 \%(\mathrm{w} / \mathrm{w})$ sucrose $(2 \mathrm{ml})$ and then with $14.3 \%(\mathrm{w} / \mathrm{w})$ sucrose $(1 \mathrm{ml})$. After centrifugation at $73,500 \mathrm{~g}\left(\mathrm{r}_{\mathrm{av}} 7.3 \mathrm{~cm}\right)$ for 2 $\mathrm{hr}$, the $\mathrm{L}$ fractions which had collected at the interface of the sucrose layers were collected by pipette, pooled and frozen-thawed three times. The denser $M$ pellets were homogenized, and frozenthawed three times before assay.

\section{ENZYME ASSAYS}

$\gamma$-Glutamyl transferase activity was determined with $L-\gamma$-glutamyl-P-nitroanilide (Sigma London Chemical Co. Ltd) as $\gamma$-glutamyl donor (24). The usual assay mixture contained $100 \mathrm{mM}$ Tris$\mathrm{HCl}$, pH 9.0, $10 \mathrm{mM} \mathrm{MgCl}_{2}, 1 \mathrm{mM} \mathrm{L- \gamma -glutamyl-P-nitroanilide,}$ $20 \mathrm{mM}$ glyclyglycine or amino acid acceptor ( $2 \mathrm{mM}$ for cystine) and enzyme in a final volume of $0.5 \mathrm{ml}$. A stock cystine solution $(4 \mathrm{mM})$ was prepared by dissolving $4.8 \mathrm{mg}$ of the free base in 50 $\mu \mathrm{l}$ of IN NaOH and diluting to $5 \mathrm{ml}$ with $0.2 \mathrm{M}$ Tris- $\mathrm{HCl}$ buffer, $\mathrm{pH}$ 9.0. After varying periods of incubation (usually $4 \mathrm{hr}$ ) at $37^{\circ} \mathrm{C}$, in which up to 60 nmole of P-nitroaniline were released, the enzyme reaction was stopped by the addition of $50 \mu \mathrm{l}$ of $50 \%$ (w/ v) trichloroacetic acid, followed 5 min later by $450 \mu$ l of $2 \mathrm{~N}$ acetic acid. After removal of any precipitate by centrifugation, the absorbance was measured at 410 nmole and compared with a standard curve prepared for P-nitroaniline in the range $0-0.1$ $\mu \mathrm{mole} / \mathrm{ml} \mathrm{M}$-acetic acid. Specific activity was calculated as nmole P-nitroaniline released per $\mathrm{mg}$ protein per $\mathrm{hr}$.

$\beta$-Glycerophosphatase was assayed at $37^{\circ} \mathrm{C}$ in a mixture containing $0.17 \mathrm{M}$ disodium $\beta$-glycerophosphate (BDH Ltd; stock solution adjusted to $\mathrm{pH} 5.0$ ), $0.07 \mathrm{M}$ sodium acetate buffer, $\mathrm{pH}$ 5.0 , and enzyme in a final volume of $60 \mu \mathrm{l}$. After a suitable incubation period, the reaction was stopped by the addition of 60 $\mu \mathrm{l}$ of $20 \%(\mathrm{w} / \mathrm{v})$ trichloroacetic acid. After centrifugation, inorganic phosphate was measured by the method of Fiske and SubbaRow (15).

Alkaline phosphatase was assayed at $37^{\circ} \mathrm{C}$ in a mixture containing $7.5 \mathrm{mM}$ P-nitrophenyl phosphate (disodium salt), $50 \mathrm{mM}$ glycine- $\mathrm{NaOH}$ buffer, $\mathrm{pH} 10.5,0.5 \mathrm{mM} \mathrm{MgCl}_{2}$ and enzyme in a final volume of $120 \mu$. After a suitable incubation period, the reaction was stopped by the addition of $1 \mathrm{ml} 20 \mathrm{mM} \mathrm{NaOH}$ and the absorbance measured at 405 nmole.

$5^{\prime}$-Nucleotidase was assayed at $37^{\circ} \mathrm{C}$ in a mixture containing 80 $\mathrm{mM}$ Tris- $\mathrm{HCl}$ buffer, $\mathrm{pH} 7.3,10 \mathrm{mM} \mathrm{MgCl}_{2}, 5 \mathrm{mM}$ disodium adenosine-5'-monophosphate and enzyme in a final volume of 1.0 $\mathrm{ml}$. After incubation for $\mathrm{l} \mathrm{hr}$, the reaction was stopped by the addition of $50 \mu \mathrm{l}$ of $50 \%(\mathrm{w} / \mathrm{v})$ trichloroacetic acid and inorganic phosphate measured after centrifugation.

Appropriate references to other enzyme assays are as follows: myeloperoxidase, automated o-tolidine method adapted to manual assay (3), $\alpha$-mannosidase and neutral $\alpha$-glucosidase (28), malate dehydrogenase and lactate dehydrogenase (20), lysozyme (25), $\mathrm{N}$-acetyl- $\beta$-D-glucosaminidase (10), glucose 6 -phosphatase (37), and $\beta$-galactosidase (45). Protein was measured according to Lowry et al. (21).

\section{RESULTS}

\section{$\gamma$-GLUTAMYL TRANSFERASE ACTIVITY OF LEUKOCYTE SUBCELLULAR FRACTIONS}

The distribution of $\gamma$-glutamyl transferase activity in normal leukocyte subcellular fractions obtained by differential centrifugation is summarized in Table 1. Distribution and total activity of the enzyme in leukocytes from patients with cystinosis were essentially similar (Table 2). Results show concentration of transferase activity in the PN granular fraction, with enrichment to a relative specific activity (RSA) of approximately 2.5 for each of the $\gamma$ glutamyl acceptors, glycylglycine, glutamine, and cystine. Similar distributions and RSA were found for the lysosomal marker activities of $\alpha$-galactosidase and acid $\beta$-glycerophosphatase. The sonication conditions used in these studies will, of course, give substantial percent of intact leukocytes that appear in the $\mathrm{N}$ 
Table 1. Distribution of enzymes in human leukocyte subcellular fractions ${ }^{1}$

\begin{tabular}{|c|c|c|c|c|c|}
\hline \multirow{2}{*}{$\begin{array}{c}\text { Marker } \\
\text { (No. of experiments) }\end{array}$} & \multicolumn{3}{|c|}{ Percent in fractions (Homogenate $=100$ ), range $($ mean) } & \multirow{2}{*}{$\begin{array}{c}\text { Recovery } \\
\text { (\% of homogenate) }\end{array}$} & \multirow{2}{*}{$\begin{array}{c}\text { Mean RSA } \\
\text { of } \\
\text { PN fraction }\end{array}$} \\
\hline & $\mathbf{N}$ & PN & $\mathbf{S}$ & & \\
\hline Protein $(7)$ & $42.0-66.8(58.3)$ & $6.1-14.2(10.2)$ & $19.7-26.3(22.7)$ & $82.4-95.6(91.2)$ & \\
\hline \multicolumn{6}{|l|}{$\gamma$-Glutamyl transferase acceptor: } \\
\hline Glycylglycine (7) & $37.5-72.5(61.8)$ & $22.6-34.5(27.4)$ & $5.9-10.5(8.1)$ & $82.5-104.5(97.3)$ & 2.70 \\
\hline L-Cystine (7) & $35.6-72.5(60.7)$ & $17.5-30.1(23.6)$ & $3.8-10.5(6.4)$ & $75.6-102.3(90.7)$ & 2.31 \\
\hline L-Glutamine (3) & $41.4-64.0(53.1)$ & $21.6-32.8(26.7)$ & $3.4-11.4(8.7)$ & $85.0-101.1(88.5)$ & 2.61 \\
\hline$\beta$-Galactosidase (6) & $52.3-75.0(65.1)$ & $25.0-40.9(31.7)$ & $1.9-13.2(6.6)$ & $89.7-114.9(103.4)$ & 3.10 \\
\hline Acid $\beta$-Glycerophosphatase (3) & $69.2-74.0(71.9)$ & $21.4-27.7(24.4)$ & $4.0-9.7(6.6)$ & $98.0-107.7(102.9)$ & 2.39 \\
\hline Lactic dehydrogenase (3) & $49.1-60.0(54.8)$ & $7.5-11.2(9.4)$ & $25.2-37.4(32.2)$ & $94.8-97.7(96.2)$ & 0.92 \\
\hline
\end{tabular}

' Enzyme assays and the isolation of leucocyte subcellular fractions were as described under Methods. RSA $=\%$ activity $/ \%$ protein.

Table 2. Distribution of enzymes in cystinotic leukocyte subcellular fractions

\begin{tabular}{|c|c|c|c|c|c|}
\hline \multirow{2}{*}{$\begin{array}{c}\text { Marker } \\
\text { (No. of experiments) }\end{array}$} & \multicolumn{3}{|c|}{ Percent in fractions (Homogenate $=100$ ), range (mean) } & \multirow{2}{*}{$\begin{array}{c}\text { Recovery } \\
\text { (\% of homogenate) }\end{array}$} & \multirow{2}{*}{$\begin{array}{c}\text { Mean RSA } \\
\text { of } \\
\text { PN fraction }\end{array}$} \\
\hline & $\mathbf{N}$ & PN & $\mathbf{S}$ & & \\
\hline $\begin{array}{l}\text { Protein (4) } \\
\gamma \text {-Glutamyl transferase acceptor: }\end{array}$ & $45.6-65.0(58.1)$ & $6.9-16.3(11.5)$ & $24.3-30.5(27.9)$ & $89.5-100.2(97.5)$ & \\
\hline Glycylglycine (4) & $54.6-67.6(61.3)$ & $26.7-37.2(31.9)$ & $5.5-8.1(6.6)$ & $95.7-109.9(99.8)$ & 2.78 \\
\hline Cystine (4) & $61.0-67.0(64.8)$ & $28.1-32.1(30.1)$ & $3.5-7.2(5.3)$ & $92.7-100.4(100.2)$ & 2.62 \\
\hline$\beta$-Galactosidase (4) & $45.2-60.5(52.5)$ & $31.3-44.6(37.3)$ & $2.7-13.6(9.2)$ & $93.4-108.4(99.0)$ & 3.24 \\
\hline
\end{tabular}

' Enzyme assays and the isolation of leukocyte subcellular fractions were as described under Methods. RSA $=\%$ activity $/ \%$ protein.

fraction. This was borne out by the distribution of lactate dehydrogenase in the fractions. Sonication did not appear to cause major disruption of lysosomes. Only a small percent of the total $\beta$-galactosidase and acid $\beta$-glycerophosphatase activities were recovered in the $S$ fraction and approximately $65 \%$ of the $\beta$-galactosidase activity of the sonicated leukocyte suspension was latent. There was also a suggestion of a low level of latency of $\gamma$-glutamyl transferase activity in the PN fraction, but this could not be confirmed satisfactorily because the assays required at least 30 min incubation. In the standard assay with glycylglycine acceptor at pH 9.0 and $37^{\circ} \mathrm{C}, \gamma$-glutamyl transferase activity of $\mathrm{PN}$ fraction was linear with protein concentrations up to $250 \mu \mathrm{g} / \mathrm{ml}$ and for incubation periods up to $6 \mathrm{hr}$. The dependence of activity on $\mathrm{pH}$ was similar to that found for the enzyme from a variety of human tissues; a pH optimum of 9.0 was chosen for routine assays, but there was little change in activity between $\mathrm{pH} 8.5$ and 9.5 in Tris$\mathrm{HCl}$ or ethanolamine- $\mathrm{HCl}$ buffers. No activity was detected in the range of $\mathrm{pH} 3.5-6.0$, and there were no differences in the activity$\mathrm{pH}$ curves for normal and cystinotic leukocyte PN fractions.

The ability of glycylglycine and various amino acids to act as acceptors of the $\gamma$-glutamyl moiety of $\gamma$-glutamyl-p-nitroanilide is shown in Table 3. In agreement with findings for the enzyme from other sources $(6,39)$, glycylglycine was the best acceptor under the assay conditions employed. Release of P-nitroaniline in the absence of acceptor was only $14 \%$ of that found in the presence of $20 \mathrm{mM}$ glycylglycine. Of the amino acids tested, L-glutamine, Lmethionine, and, particularly, L-cystine were good acceptors, whereas even after prolonged incubation no definite activity was observed with glycine, L-aspartate, L-leucine, L-isoleucine, L-valine, L-histidine, L-lysine, or L-proline. The high acceptor activity of cystine is especially notable in view of its low solubility, which necessitated an assay concentration of $2 \mathrm{mM}$ compared to $20 \mathrm{mM}$ for all other acceptors, and is best expressed by comparison of Michaelis constants. For PN fractions from normal leukocytes, using $1 \mathrm{mM} \gamma$-glutamyl-P-nitroanilide, values of apparent $K_{m}$ and $\mathrm{V}$ obtained from Lineweaver-Burk plots and a computer program for linear regression were, respectively, $1.3 \mathrm{mM}$ and $0.46 \mu \mathrm{mole} /$ $\mathrm{hr} / \mathrm{mg}$ protein for cystine; 8.7 and 0.17 for glutamine; 6.7 and 0.20 for glycylglycine. $\mathrm{K}_{\mathrm{m}}$ for cystine determined for the PN fraction of cystinotic leukocytes was also $1.3 \mathrm{mM}$. $\gamma$-Glutamyl transferase activity of the PN fraction differed markedly from that of the $\mathrm{N}$ fraction or total homogenate in its thermal stability in $10 \mathrm{mM}$ Tris- $\mathrm{HCl}, \mathrm{pH} 7.5$. After $60 \mathrm{~min}$ at $58^{\circ} \mathrm{C}$ only $19 \%$ of $\mathrm{PN}$ fraction
Table 3. Effect of different acceptors on the $\gamma$-glutamyl transferase activity of human leucocyte $27,000 \mathrm{~g} P N$ granule fraction ${ }^{1}$

\begin{tabular}{lc}
\multicolumn{1}{c}{ Acceptor } & Activity \% \\
\hline Glycylglycine & 100 \\
L-cystine $(2 \mathrm{mM})$ & 50 \\
L-glutamine & 28 \\
L-methionine & 28 \\
L-arginine & 21 \\
L-alanine & 18 \\
L-glutamate & 16 \\
L-phenylalanine & 16 \\
L-asparagine & 14 \\
L-ornithine & 14 \\
L-serine & 14 \\
L-aspartate & \\
Glycine & \\
L-histidine & \\
L-leucine & 12 \\
L-isoleucine & \\
L-valine & \\
L-lysine & \\
L-proline & \\
None & 12 \\
\hline
\end{tabular}

' The enzyme assay was as described under Methods, using $50 \mu \mathrm{g}$ of fraction protein per assay incubated for $4 \mathrm{hr}$. With the exception of cystine $(2 \mathrm{mM})$, the final acceptor concentration was $20 \mathrm{mM}$.

activity remained, compared to 67 and $74 \%$ for $\mathrm{N}$ fraction and homogenate, respectively. Similar results were obtained when the protein content of the $\mathrm{PN}$ fraction was adjusted to that of the $\mathrm{N}$ fraction by addition of bovine serum albumin. No differences between fractions from normal and cystinotic leukocytes were observed.

\section{FRACTIONATION BY ISOPYCNIC SUCROSE GRADIENT} CENTRIFUGATION

Typical distribution histograms of enzymic activities after isopycnic centrifugation of a leukocyte $P N$ fraction in a sucrose gradient of density 1.15-1.30 are shown in Figure 1. This pattern was unchanged on centrifugation for $1.5 \mathrm{hr}, 2.0 \mathrm{hr}$, or $2.5 \mathrm{hr}$ and was reproduced closely in nine similar experiments using normal 

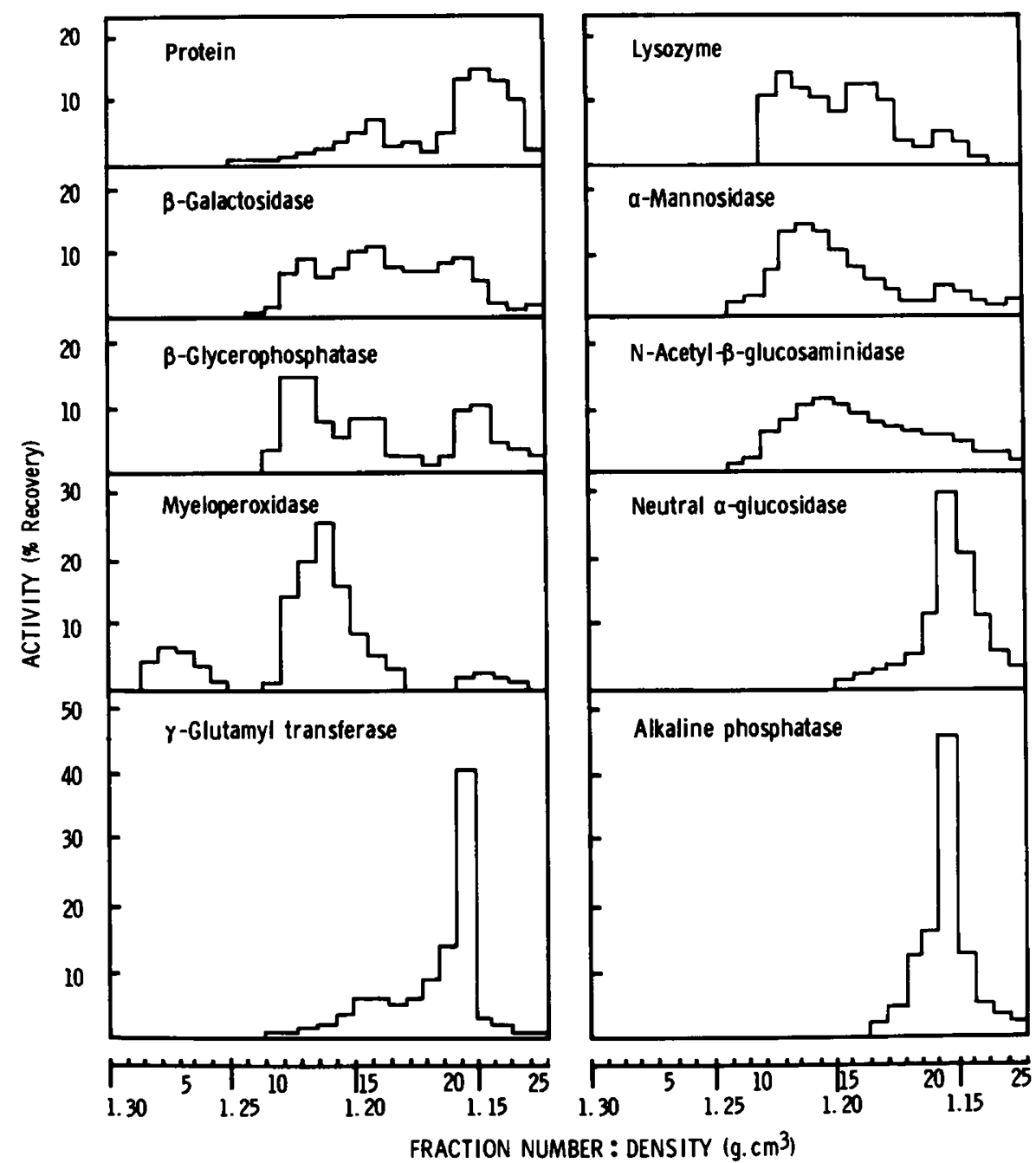

Fig. 1. Isopycnic centrifugation of the $600 \mathrm{~g}$ S fraction of sonicated human leukocytes. Leukocyte preparation, centrifugation conditions, and enzyme assays were as described under Methods.

leukocytes and six using leukocytes from cystinotic patients. Similar results with respect to $\gamma$-glutamyl transferase, alkaline phosphatase, acid $\beta$-glycerophosphatase, and lysozyme were also obtained for a normal granulocyte concentrate. Four turbid bands with modal densities of approximately $1.19,1.21,1.22$, and 1.24 were visible in the gradient after centrifugation at $115,000 \mathrm{~g}$ for 2 $\mathrm{hr}$. A further band was separated near the junction of the gradient and applied sample volumes. The latter band (density approximately 1.15) contained virtually all of the applied alkaline phosphatase and neutral $\alpha$-glucosidase activities, and indicates that the agglutination of microsomal components or possibly specific granules with denser particles was not a serious factor. The absence of agglutination was also indicated by the failure to detect these enzymic activities in the high density regions of the gradient. Approximately $80 \%$ of the $\gamma$-glutamyl transferase activity (cystine or glycylglycine acceptor) and some acid hydrolase activity including a well-defined band of acid $\beta$-glycerophosphatase were also found in the 1.15 density region. The remainder of the $\gamma-$ glutamyl transferase was clearly and consistently separated from the alkaline phosphatase fractions and was present in gradient regions containing activity for various acid hydrolases at density 1.19-1.20. The range and (mean) of the combined \% recoveries of $\gamma$-glutamyl transferase activity in fractions of this density (15 and 16) were, for nine normal leukocyte preparations, 10.7-18.5 (14.2); and for six cystinotic preparations, 7.4-14.6 (11.1). The single normal granulocyte preparation gave a value of 13.1. Heterogeneity of hydrolase-containing (lysosomal) particles was suggested by the spread of activity into higher density regions of the gradient; in particular, acid $\beta$-glycerophosphatase, $\beta$-galactosidase, $\beta$-glu- cosaminidase, and $\alpha$-mannosidase showed further substantial activities at density 1.21-1.22. Myeloperoxidase activity, whereas showing a small peak with negligible hydrolase activity at density 1.27 was mainly found in the hydrolase particles of density 1.21 1.22 .

Mitochondria are present only in relatively small numbers in leukocytes, but would be expected to be recovered in the PN fraction. However, with the low cell numbers employed in these experiments, no malate dehydrogenase activity could be detected in any region of the gradient. Furthermore, the densities of the sedimenting hydrolase bands were different from that (1.17) reported for mitochondria of human leukocytes (34).

Hydrolase activities exhibited varying degrees of latency throughout the fractions, but it was not feasible to test for possible latency of $\gamma$-glutamyl transferase activity over the $4 \mathrm{hr}$ incubation required for assay. There were no differences in the $\mathrm{pH}$ activity curves for the two $\gamma$-glutamyl transferase regions of the gradient, for which the individual values of $K_{m}$ for cystine and glycylglycine were similar and in approximate agreement with the values found for the total PN fraction.

5 -Nucleotidase activity was not detectable in the leukocyte gradients. Our findings confirm the absence of this plasma membrane marker in human neutrophiles (38).

\section{$r$ GLUTAMYL TRANSFERASE ACTIVITY OF MODIFIED LYSOSOMES FROM RAT LIVER}

The distribution of activities of $\gamma$-glutamyl transferase and marker enzymes for subcellular components resulting from the 
flotation procedure for the purification of Triton WR-1339-modified rat liver lysosomes is given in Table 4. Protein and acid phosphatase distribution and the relative specific activity of acid phosphatase in the $\mathbf{L}$ fraction were in close agreement with reported average values (42). Whereas the proportion of $\gamma$-glutamyl transferase (approximately 7\%) found in the $\mathrm{L}$ fraction was relatively small compared with the amounts present in the $\mathrm{N}$ and $25 S$ fractions, the $L$ fraction was enriched in transferase to a RSA of approximately 11 , because it contained only $0.6 \%$ of the protein in the combined cell fractions. Some contamination of the $\mathbf{L}$ and the $\mathbf{M}$ fractions by nonlysosomal membranous components including the plasma membrane is indicated by the distribution of the membrane marker enzymes 5'-nucleotidase and glucose 6phosphatase. However, a comparison of the relative proportions $(\mathrm{L} / \mathrm{M})$ of these activities and that of $\gamma$-glutamyl transferase in the $L$ and $M$ fractions suggests that the bulk of the transferase activity of the $\mathrm{L}$ fraction was not attributable to contamination by the plasma membrane or endoplasmic reticulum. Contamination of $\mathbf{L}$ fraction by mitochondria was negligible judging by the absence of malate dehydrogenase activity.

\section{HISTOCHEMICAL OBSERVATIONS}

Further evidence that some transpeptidase activity is associated with lysosomes was obtained from study of rabbit bone marrow cells in which considerable information is available about the maturational pattern of subcellular organelles in neutrophile precursors. The results show clearly the presence of specific staining for $\gamma$-glutamyl-transpeptidase activity in marrow leukocytes. Intense focal staining is seen presumably corresponding to an intracellular granule locus (Fig. 2). The margins of the cell show some small, but comparatively weak activity. The presence of consid-

Table 4. Distribution of enzymes in subcellular fractions of rat liver after preinjection of Triton WR 1339

\begin{tabular}{|c|c|c|c|c|c|c|c|}
\hline & \multicolumn{3}{|c|}{$\begin{array}{l}\text { Percent in fractions (Homoge- } \\
\text { nate }=100 \text { ) }\end{array}$} & \multirow[b]{2}{*}{$\mathbf{M}$} & \multirow{2}{*}{$\frac{\mathrm{L}}{\mathrm{M}}$} & \multirow{2}{*}{$\begin{array}{c}\text { Recovery } \\
\text { (\% homogenate) } \\
\end{array}$} & \multirow{2}{*}{$\begin{array}{l}\text { RSA of } \\
L \text { fraction }\end{array}$} \\
\hline & $\mathbf{N}$ & $25 \mathrm{~S}$ & $\mathbf{L}$ & & & & \\
\hline Protein & 31.2 & 47.0 & 0.6 & 18.5 & 0.03 & 97.3 & \\
\hline \multicolumn{8}{|l|}{$\gamma$-Glutamyl transferase acceptor: } \\
\hline Cystine & 53.2 & 28.3 & 6.8 & 2.2 & 3.09 & 90.5 & 11.3 \\
\hline Glycylglycine & 54.5 & 34.2 & 6.9 & 3.3 & 2.09 & 98.9 & 11.5 \\
\hline Acid $\beta$-Glycerophosphatase & 25.7 & 30.2 & 19.2 & 19.0 & 1.01 & 94.1 & 32.0 \\
\hline Alkaline phosphatase & 25.7 & 37.5 & 3.5 & 46.0 & 0.08 & 112.9 & 5.8 \\
\hline Glucose 6-phosphatase & 17.6 & 49.1 & 0.6 & 32.6 & 0.02 & 99.9 & 1.0 \\
\hline $5^{\prime}$-Nucleotidase & 48.5 & 31.1 & 6.0 & 13.1 & 0.46 & 98.7 & 10.0 \\
\hline Malate dehydrogenase & 11.1 & 34.0 & $\begin{array}{l}\text { not } \\
\text { detected }\end{array}$ & 66.4 & 0 & 111.5 & \\
\hline
\end{tabular}

'Enzyme assays and the isolation of liver subcellular fractions were as described under Methods, RSA $=\%$ activity $/ \%$ protein.
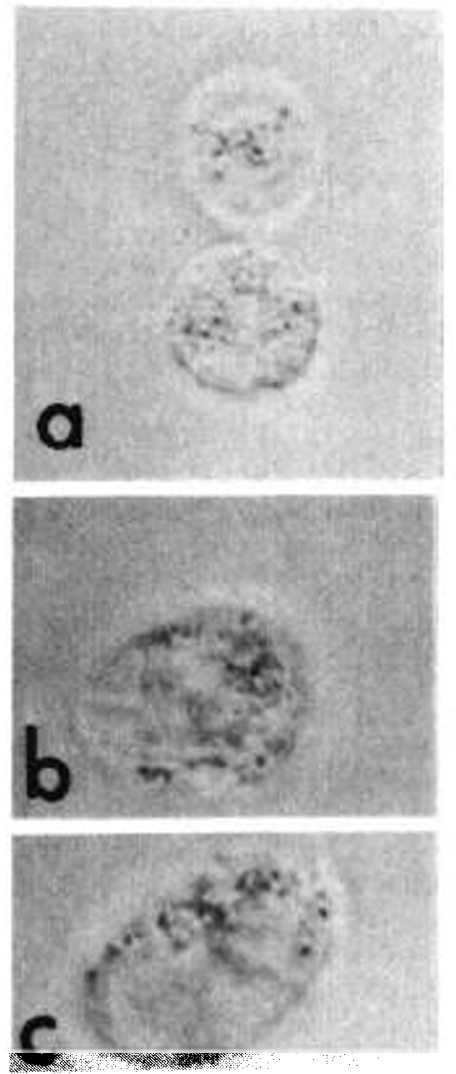
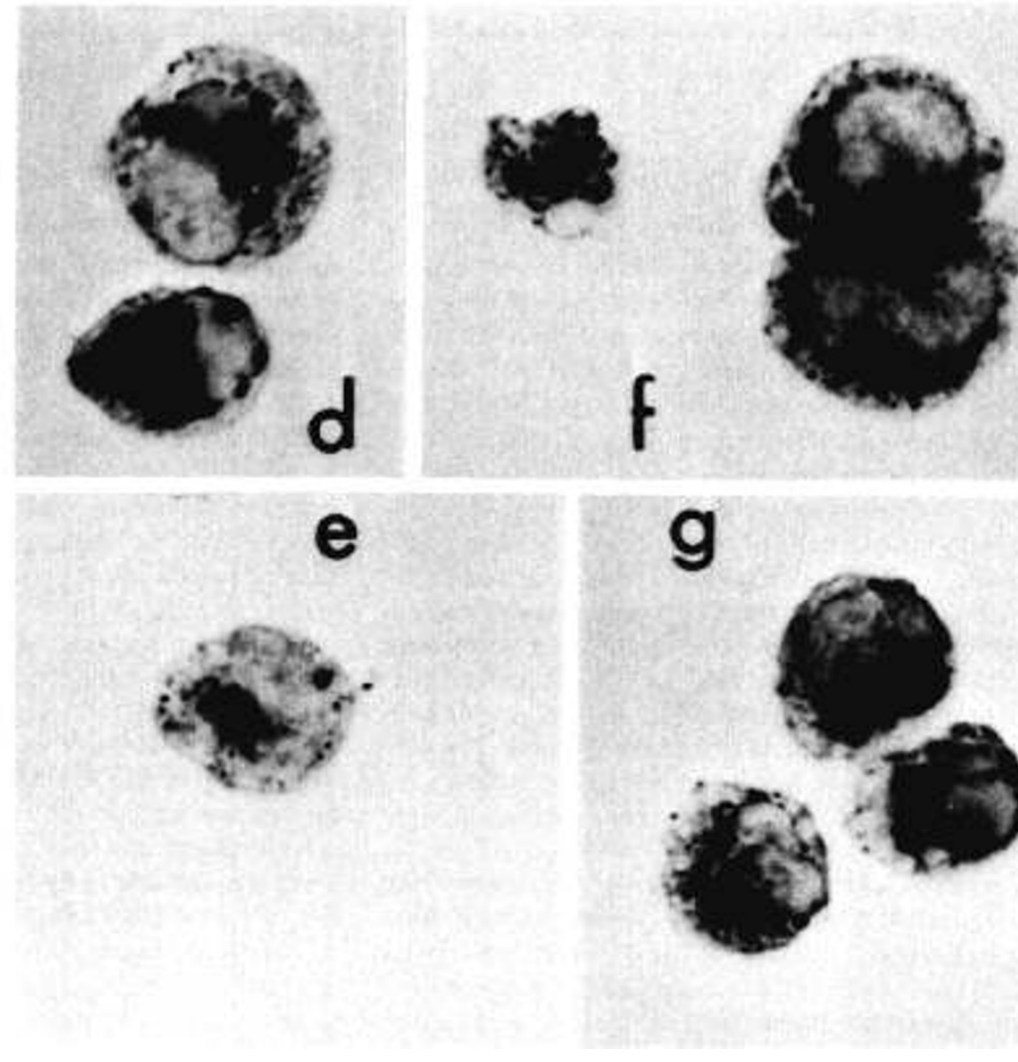

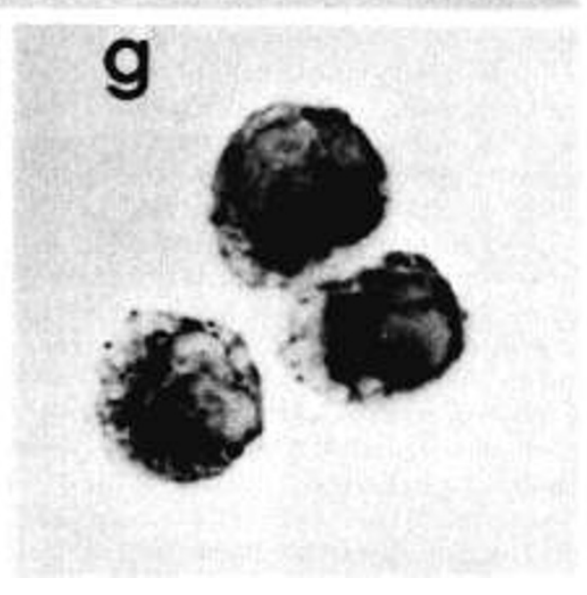

Fig. 2. $\gamma$-Glutamyl transpeptidase activity of rabbit bone marrow. Representative cells are shown. $a-c$ ) Controls incubated in the absence of substrate: $a$ ) top-probably metamyelocyte; below-mature polymorphonuclear leukocyte; $b$ ) myelocyte; $c$ ) promyelocyte. $d-g$ ) As for $a-c$, but with substrate: $d$ ) myeolocyte (top) and metamyelocyte; $e$ ) metamyelocyte; $f$ ) polymorphonuclear leukocyte, myelocyte (top), and probable promyelocyte; $g$ ) other myelocytes of varying maturity. 
erable particulate intracellular activity was demonstrated even in early stages of maturation, during which the synthesis of azurophile (lysosomal) granules is known to predominate over synthesis of specifics (4).

\section{DISCUSSION}

The occurrence of a component of the $\gamma$-glutamyl transferase activity of human leukocytes in a PN granule fraction of mildly disrupted cells and in the acid-hydrolase region on isopycnic centrifugation suggests that this enzyme might be a constituent of lysosomes.

Several characteristics of the transferase in the PN fraction were similar to those of the nuclear fraction or whole homogenate. The enzyme exhibited a broad $\mathrm{pH}$ optimum between $8.5-9.5$, with no evidence of activity in the acid range. This is the first report suggesting that an enzyme associated with lysosomes might have a distinctly alkaline pH optimum; but other lysosomal enzymes are known that are optimally active at neutral $\mathrm{pH}$ or above. Values of apparent $\mathrm{K}_{\mathrm{m}}$ and $\mathrm{V}$ for reactions involving cystine, glutamine, or glycylglycine as acceptors were also in close agreement for the different fractions. A notable feature previously reported by us $(32,33)$, and independently observed by Thompson and Meister (40) for the rat kidney enzyme, is the demonstration that cystine is a potent acceptor of the $\gamma$-glutamyl moiety of $\gamma$-glutamyl Pnitroanilide. In agreement with previous findings $(6,39)$, glycylglycine and the neutral amino acids L-methionine and L-glutamine were also good acceptors, but no activity could be detected with L-aspartate, L-histidine, L-lysine, L-proline, glycine, or the branched-chain amino acids.

$\gamma$-Glutamyl transferase of the PN fraction was considerably more heat-labile than that of the $\mathrm{N}$ fraction. This suggests that the enzyme might be bound differently to particles in the two fractions or that there might be different molecular forms of the enzyme in these two locations.

When leukocyte granules such as those described above were first isolated and shown to have lysosomal properties, they were assumed to be primary lysosomes $(11,12)$. However, the presence in these granule preparations of a heterogeneous population of particles was suggested by morphologic differences and by the inclusion of membrane-bound enzymes, such as alkaline phosphatase, not normally found in lysosomes $(12,44)$. In subsequent studies on rabbit heterophil leukocytes by zonal sedimentation and isopycnic centrifugation, four types of particles were identified $(2,3,14)$. Four sedimenting bands and a nonsedimenting band that collected at the junction of the gradient and sample volumes were also visible after isopycnic centrifugation of $\mathrm{PN}$ fractions of human leukocytes. Unlike rabbit leukocytes, in which the bulk of the alkaline phosphatase was assigned to the specific (secondary) lysozyme-containing granules (2), all of the alkaline phosphatase (substrate, P-nitrophenyl phosphate) of human leukocyte granule preparations was confined to a sharp band of particles of modal density approximately 1.15 and which contained only a small amount of lysozyme. A similar distribution of alkaline phosphatase after isopycnic centrifugation of human leukocyte granules was found by Schulman et al. (31). The fact that neutral $\alpha$ glucosidase, which has been shown to have a microsomal localization in a number of tissues $(19,35)$ was also confined to this band suggests that it was derived from the endoplasmic reticulum. Other membrane components are also normally recovered with the microsomal fraction, but neither 5 '-nucleotidase (plasma membrane) nor malate dehydrogenase (part mitochondrial) activities were detected in any region of the gradient.

Whereas the bulk of the $\gamma$-glutamyl transferase activity was localized to the alkaline phosphatase particles, with little, if any, appearing to be in the cytosol, a small, but significant amount (approximately $20 \%$ ) was clearly separated in a hydrolase-containing band that sedimented with a modal density of 1.19. The presence of lysozyme, myeloperoxidase, $\beta$-glucosaminidase, $\beta$-galactosidase, $\alpha$-mannosidase, and acid $\beta$-glycerophosphatase in this region of the gradient suggests strongly that some transferase activity is consistently associated with the lysosomal primary azurophil granules.

The evidence for localization of some $\gamma$-glutamyl transferase in lysosomal particles in neutrophiles is further substantiated by our histochemical studies of rabbit neutrophile precursors in bone marrow. Intracellular granules strongly positive for the enzyme were demonstrated during neutrophile differentiation not only in mature neutrophiles, but during those developmental stages when azurophile (lysosomal) granules are the predominant cytoplasmic organelles.

Evidence was also obtained that the transpeptidase occurs in lysosomes in rat liver. This is attested by its marked enrichment in the purified lysosomal fraction prepared from the livers of rats preinjected with Triton WR-1339. As discussed above, the data from Table 4 indicates that the bulk of $\gamma$-glutamyltransferase activity in rat liver lysosomes is not explicable as simple contamination of this fraction with plasma membrane.

Seymour et al. (35) reported that the $\gamma$-glutamyl transferase activity of PN supernatant from normal human liver showed a complex distribution pattern after isopycnic centrifugation. Whereas there seems little doubt that the transpeptidase has a complex subcellular distribution, the evidence presented here from biochemical and morphologic studies in three different cellular systems indicates that some $\gamma$-glutamyl transpeptidase activity is normally found in association with lysosomal particles. Additional support for this conclusion can be found in the work of Binkley et al. (8) who did some of the early biochemical studies of this enzyme; they reported that the $\gamma$-glutamyl transferase activity of subcellular fractions of kidney was not associated with brush border membranes, but was confined to smooth membrane vesicles involved in the exocytic and endocytic transport of proteins, functions characteristics of the phagolysosomal system (8). Histochemical procedures have also provided evidence of discrete subcellular localization of the enzyme. Albert et al. (1) demonstrated $\gamma$-glutamyl transferase activity in cytoplasmic granules in some reticuloendothelial cells of guinea pig, rat, and rabbit spleen, and in hepatocytes of guinea pig and rabbit, and activity localized to granules has been found in the cytoplasm of rat lymphocytes and monocytes (36).

A possible function of $\gamma$-glutamyl transferase in the transport of amino acids, its occurrence in the lysosomal system and high activity towards cystine as $\gamma$-glutamyl acceptor, raised the question whether a deficiency of the enzyme might explain the intralysosomal storage of cystine in the tissues of patients with cystinosis. In these studies, no evidence was obtained suggesting an abnormality in the total or component (including lysosomal) activities of the transferase in the leukocytes of cystinotic patients. Normal total activities were also found in liver, kidney, spleen, and cultured skin fibroblasts from such patients (33).

When the studies reported in the present manuscript were largely completed, the authors and others described a patient manifesting prominent glutathionuria and a severe deficiency of $\gamma$-glutamyl transpeptidase in serum (16) and cultured fibroblasts $(27,32)$. The patient did not have a cystinotic phenotype. Transcellular amino acid transport in fibroblasts (27) and kidney (32) in this patient were normal. Studies on this patient support other evidence (7) that the role of the transpeptidase in amino acid transport across the cell membrane must be seriously questioned. In cystinosis, cystine is compartmentalized in lysosomes. The present studies demonstrate clearly that a selective deficiency of the transpeptidase in lysosomes cannot be demonstrated in cases of human cystinosis, even though the enzyme is normally found in association (but not exclusive association) with these subcellular organelles.

The data provided here also form the basis of the observation, first reported by the authors in abstract (33) and independently documented by Thompson and Meister (40) that L-cystine is the most potent of the natural amino acids as a $\gamma$-glutamyl acceptor in the amino acid transfer reaction catalyzed by $\gamma$-glutamyl transpeptidase. 


\section{REFERENCES AND NOTES}

1. Albert, Z., Orlowski, M., and Szewczuk, A.: Histochemical demonstration of $\gamma$ glutamyl transpeptidase. Nature (London) 191: 767 (1961).

2. Baggiolini, M.. Hirsch. J. G., and de Duve, C.: Further biochemical and morphological studies of granule fractions from rabbit heterophil leukocytes. J. Cell. Biol., 45: 586 (1970).

3. Baggiolini, M., Hirsch, J. G., and de Duve. C.: Resolution of granules from rabbit heterophil leukocytes into distinct populations by zonal sedimentation. J. Cell Biol., 40: 529 (1969).

4. Bainton. D. F.. and Farquhar, M. G.: Origin of granules in polymorphonuclear leukocytes. J. Cell Biol., 28: 277 (1966).

5. Binkley, F.: Metabolism of glutathione. Nature (London), 167: 888 (1951).

6. Binkley. F.: Purification and properties of renal glutathionase. J. Biol. Chem., 236: 1075 (1961)

7. Binkley, F., and Johnson. J. D.: $\gamma$-Glutamyl cycle. Science. 184: 586 (1974).

8. Binkley. F.. Wiesemann, M. L.. Gorth. D. .. and Powell, R. W.: $\gamma$-Glutamyl transferase: a secretory enzyme. FEBS Lett., S1: 168 (1975).

9. Bodnaryk, R. P.: Membrane-bound- $\gamma$-glutamyl transpeptidase. Evidence that it is a component of "Amino Acid Site" of certain amino acid transport systems. Can. J. Biochem.. 50: 524 (1972).

10. Brett. E. M.. Ellis. R. B., Haas, L., Ikonne, J. U., Lake, B. D., Patrick. A. D., and

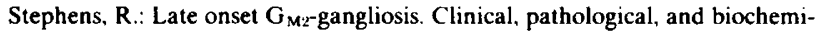
cal studies on eight patients. Arch. Dis. Childhood, 48: 775 (1973).

11. Cohn, Z. A., and Hirsch, J. G.: The influence of phagocytosis on the intracellular distribution of granule-associated components of polymorphonuclear leukocytes. J. Exptl. Med., /12: 1015 (1960)

12. Cohn, Z. A., and Hirsch, J. G.: The isolation of properties of the specific cytoplasmic granules of rabbit polymorphonuclear leukocytes. J. Exptl. Med., II2: 983 (1960).

13. Connell, G. E., and Hanes, C. S.: Enzymatic formation of pyrrolidone carboxylic acids from $\gamma$-glutamyl peptides. Nature (London). 177: 377 (1956)

14. Farquhar, M. G., Bainton, D. F., Baggiolini, 1. M., and de Duve, C.: Cytochemical localization of acid phosphatase activity in granule fractions from rabbit polymorphonuclear leukocytes. J. Cell. Biol., 54: 141 (1972).

15. Fiske, C. H., and SubbaRow, Y.: Colorimetric determination of phosphorus. J. Biol. Chem., 66: 375 (1925).

16. Goodman. S. I., Mace, J. W., and Pollak, S.: Serum $\gamma$-glutamyl transpeptidase deficiency. Lancet, 1: 234 (1971).

17. Hanes, C. S., Hird, F. J. R., and Isherwood, F. A.: Enzymatic transpeptidation reactions involving $\gamma$-glutamyl peptides and $\alpha$-amino-acyl peptides. Biochem. J., $51: 25$ (1952).

18. Hanes, C. S., Hird, F. J. R., and Isherwood. F. A.: Synthesis of peptides in enzymatic reactions involving glutathione. Nature (London), 166: 288 (1950).

19. Lejuene. N., Thines-Sempoux. D., and Hers. H. G.: Tissue fractionation studies. Intracellular distribution and properties of $\alpha$-glucosidases in rat liver. Biochem. J., 86: 16 (1963).

20. Lowry, O. H., Roberts, N. R., and Kapphahn, J. H.: The fluorometric measurement of pyridine nucleotides. J. Biol. Chem., 224: 1047 (1957).

21. Lowry, O. H.. Rosebrough, N. J., Farr, A. L., and Randall, R. J.: Protein measurement with the Folin phenol reagent. J. Biol. Chem., 193: 265 (1951).

22. Meister. A.: On the enzymology of amino acid transport. Science. 180: 33 (1973).

23. Orlowski, M., and Meister, A.: $\gamma$-Glutamyl cycle: a possible transport system for amino acids. Proc. Natl. Acad. Sci. USA, 67: 1248 (1970).

24. Orlowski, M., and Meister, A.: $\gamma$-Glutamyl-P-nitroanilide: A new convenient substrate for determination and study of $L-$ and $D-\gamma$-glutamyl transpeptidase activities. Biochem. Biophys. Acta, 73: 679 (1963).

25. Parry, R. M., Chandan, R. C., and Shahani, K. M.: A rapid and sensitive assay of muramidase. Proc. Soc. Exptl. Biol. Med., 119: 384 (1965).

26. Patrick. A. D., and Lake, B. D.: Cystinosis: electron microscope evidence of

Copyright (C) 1979 International Pediatric Research Foundation. Inc $0031-3998 / 79 / 1309-1058 \$ 02.00 / 0$ lysosomal storage of cystine in lymph node. J. Clin. Pathol., 21: 571 (1968)

27. Pellifigue, F., Butler, J. deB., Spielberg, S. P., Morley, H. M., Goodman. S. I., and Schulman, J. D.: Normal amino acid uptake by cultured human fibroblasts does not require $\gamma$-glutamyl transpeptidase. Biochem. Biophys. Res. Commun., 73: 997 (1976).

28. Peters, T. J., Muller, M. and de Duve, C.: Lysosomes of the arterial wall. I Isolation and subcellular fractionation of cells from normal rabbit aorta. $J$. Exptl. Med., 136: 1117 (1972)

29. Rutenberg. A. M., Kim, H., Fischbein, J. W., Hanker, J. S., Wassenbrug. H. L. and Seligman. A. M.: Histochemical and ultrastructural demonstration of $\gamma$ glutamyl transpeptidase activity. J. Histochem. Cytochem.. 17: 517 (1969).

30. Schneider, J. A., Bradley, K. H., and Seegmiller, J. E.: Transport and intracellular fate of cysteine-"15 in leukocytes from normal subjects and patients with cystinosis. Pediatr. Res., 2: 441 (1968).

31. Schulman, J. D., Bradley, K. H., and Seegmiller. J. E.: Cystine: compartmentalization within cystinotic leukocytes. Science, 166: 1152 (1969).

32. Schulman, J. D., Goodman, S. I., Mace, J. W., Patrick, A. D., Tietze, F., and Butler, E. J.: Glutathionuria: inborn error of metabolism due to tissue deficiency of $\gamma$-glutamyl transpeptidase. Biochem. Biophys. Res. Commun., 65: 68 (1975).

33. Schulman, J. D., Patrick, A. D., Goodman, S. I., Tietze, F., and Butler. J.: $\gamma$ Glutamyl transpeptidase: investigations in normals and patients with inborn errors of sulfur metabolism. Pediatr. Res. 9: 355 (1975).

34. Schultz, J., Corlin, R., Oddi. F.. Kaminker, K., and Jones, W.: Myeloperoxidase of the leukocyte of normal human blood (isolation of the peroxidase granule) Arch. Biochem., 11l: 73 (1965).

35. Seymour, C. A., Neale, G., and Peters. T. J.: Analytical subcellular fractionation studies on human liver biopsies. Biochem. Soc. Trans., 2: 1101 (1974).

36. Shrader, R. E., and Hurley, L. S.: Enzyme histochemistry of peripheral blood and bone marrow in zinc-deficient rats. Lab. Invest., 26: 566 (1972).

37. Spencer-Peet, J., Norman, M. E., Lake. B. D.. McNamara. J., and Patrick, A. D. Hepatic glycogen storage disease (clinical and laboratory findings in 23 cases). Quart. J. Med., 40: 95 (1971).

38. Strauss, R. G., and Burrows, S. E.: Correspondence with editor. Blood, 46: 655 (1975).

39. Tate, S. S., and Meister, A.: Interaction of $\gamma$-glutamyl transpeptidase with amino acids, dipeptides, and derivatives and analogs of glutathione, J. Biol. Chem., 249: 7593 (1974)

40. Thompson, G. A., and Meister, A.: Utilization of L-cystine by the $\gamma$-glutamyl transpeptidase- $\gamma$-glutamyl cyclotransferase pathway. Proc. Natl. Acad. Sci. USA, 72: 1985 (1975).

41. Trouet, A.: Immunization de lapins par les lysosomes hépatiques de rats traités au Triton WR 1339. Arch. Intern. Physiol. Biochem., 72: 698 (1964).

42. Trouet, A.: Isolation of modified liver lysosomes. In: S. Fleischer and L. Packer. Methods in Enzymology. (New York, Academic Press, 1974).

43. Van der Werf, P.. Orlowski, M. and Meister, A.: Enzymatic conversion of 5-oxoL-proline (L-pyrrolidine) to L-glutamate coupled with cleavage of adenosine triphosphate to adenosine diphosphate. a reaction in the $\gamma$-glutamyl cycle. Proc. Natl. Acad. Sci. USA, 69: 2982 (1971).

44. Wetzel, B. K., Horn, R. G., and Spicer, S. S.: Fine structural studies on the development of heterophil, eosinophil, and basophil granulocytes in rabbits. Lab. Invest., 16: 349 (1967)

45. Young, E., Ellis, R. B., and Patrick, A. D.: Leukocyte $\beta$-galactosidase activity in $\mathrm{GM}_{1}$-gangliosidosis (Letter to Editor). Pediatrics, 50: 502 (1972).

46. This research was supported in part, by grant CA 15544 from NIH (R.D.B.).

47. Requests for reprints should be addressed to: Dr. J. Schulman, National Institutes of Health, Building 10, Room 13N260, 9000 Rockville Pike, Bethesda, Maryland 20014 (USA).

48. Received for publication November 30, 1976.

49. Accepted for publication September 26, 1978. 